\title{
EL MIEDO EN EDUCACIÓN FÍSICA: UNA HISTORIA RECONOCIBLE
}

\author{
O MEDO EM EDUCAÇÃO FÍSICA: UMA HISTÓRIA RECONHECÍVEL
}

FEAR IN PHYSICAL EDUCATION: A RECOGNIZABLE STORY

Javier Monforte, Víctor Pérez-Samaniego*

\section{Palabras clave:}

Emociones.

Currículum oculto.

Narrativa.

Prácticas analíticas

creativas.
Resumen: El miedo condiciona la manera de vivir, aprender y crecer en la escuela. Partiendo de datos etnográficos, este estudio explora la experiencia de miedo en Educación Física (EF) por medio de una perspectiva narrativa. Para analizar los datos y comunicar los resultados se utilizan prácticas analíticas creativas. El núcleo del artículo es una historia contada por Eva, una alumna que se enfrenta a un examen de EF. Su mirada evoca qué hace el miedo en diversos ambientes narrativos. La historia se presenta como un recurso para pensar con y sobre la experiencia del miedo en EF.
Palavras chave:

Emoções.

Curriculum oculto.

Narrativa.

Práticas analíticas

criativas.
Resumo: 0 medo condições como viver, aprender e crescer na escola. Com base em dados etnográficos, este estudo explora a experiência do medo em Educação Física (EF) através de uma perspectiva narrativa. Para analisar os dados e relatar os resultados foram utilizadas práticas analíticas criativas. 0 núcleo do artigo é uma história contada por Eva, uma estudante que enfrenta um exame de EF. Seu olhar evoca que faz ele medo em vários ambientes narrativos. A história é apresentada como um recurso para 0 pensamento e a experiência do medo em EF.

Abstract: Fear determines how students live, learn and grow up in schools. Drawing on

Keywords:

Emotions.

Hidden curriculum.

Narrative.

Creative analytical

practices. ethnographic data, this study explores fear experience in Physical Education (PE) through a narrative perspective. Creative analytical practices were used to analyse data and represent findings. The core of the paper is a story told by Eva, a student who faces a PE exam. Through her gaze, the story shows rather than tells what fear does within several narrative environments. The story is offered as a resource to think with and about fear experienced in $\mathrm{PE}$.
*Universitat de València. Valencia, España.

E-mail: javier.monforte@uv.es; victor.m.perez@uv.es

Recebido em: 11-02-2016 Aprovado em: 17-01-2017

(c) (1) (8) Licence 


\section{INTRODUCCIÓN}

Este artículo explora cómo es, cómo opera y qué efectos produce el miedo en EF. El miedo puede marcar la manera de vivir, aprender y crecer en esta materia. Comprender cómo funciona y cómo podemos relacionarnos con él resulta necesario para mejorar la vida en las aulas, especialmente la de aquellas personas para las que el miedo resulta una experiencia negativa y limitante.

De acuerdo con Tamminen y Bennett (2016), Tamminen et al. (2016) y Jackson (2010), podemos distinguir dos enfoques básicos a la hora de concebir y estudiar el miedo: el intrapersonal y el social-relacional. El enfoque dominante, el intrapersonal, considera el miedo una reacción psicobiológica a estímulos concretos, y centra su interés en explicar las causas, los efectos y la incidencia de dichos estímulos. En el campo educativo, los estudios previos asentados en este supuesto focalizan la atención en el miedo del alumnado ante distintos elementos del currículum, especialmente los exámenes (PUTWAIN, 2009; PUTWAIN; REMEDIOS; SYMES, 2015). En contraste, el enfoque social-relacional busca comprender los significados personales y grupales del miedo, así como sus implicaciones sociales, políticas y culturales. Se considera que el miedo es una experiencia situada en contextos relacionales concretos, por lo que el estudio de sus significados y consecuencias no puede separarse de la comprensión de dichos contextos. Del mismo modo, se reconoce que el miedo constituye una práctica discursiva y cultural conectada a desigualdades materiales e históricas, y que se (re)produce en y dentro de las relaciones sociales de poder (KUBY, 2014; BOURKE, 2015).

El enfoque social-relacional resulta particularmente apropiado para comprender cómo actúa y cómo se vive el miedo en la EF debido a que el alumnado de EF está constantemente interactuando entre sí, con el profesorado y con otros agentes educativos (TAMMINNEN et al., 2016). Asimismo, comprender el miedo como una forma de interacción social resulta pertinente para distinguir las estructuras sociales latentes que conforman el miedo, así como las dinámicas de poder que toman cuerpo en la experiencia particular del miedo que se vive en el aula (MCNAY, 2004). Dentro de este enfoque general, la figura 1 ilustra nuestra concepción de la experiencia del miedo.

Figura 1 - La experiencia del miedo

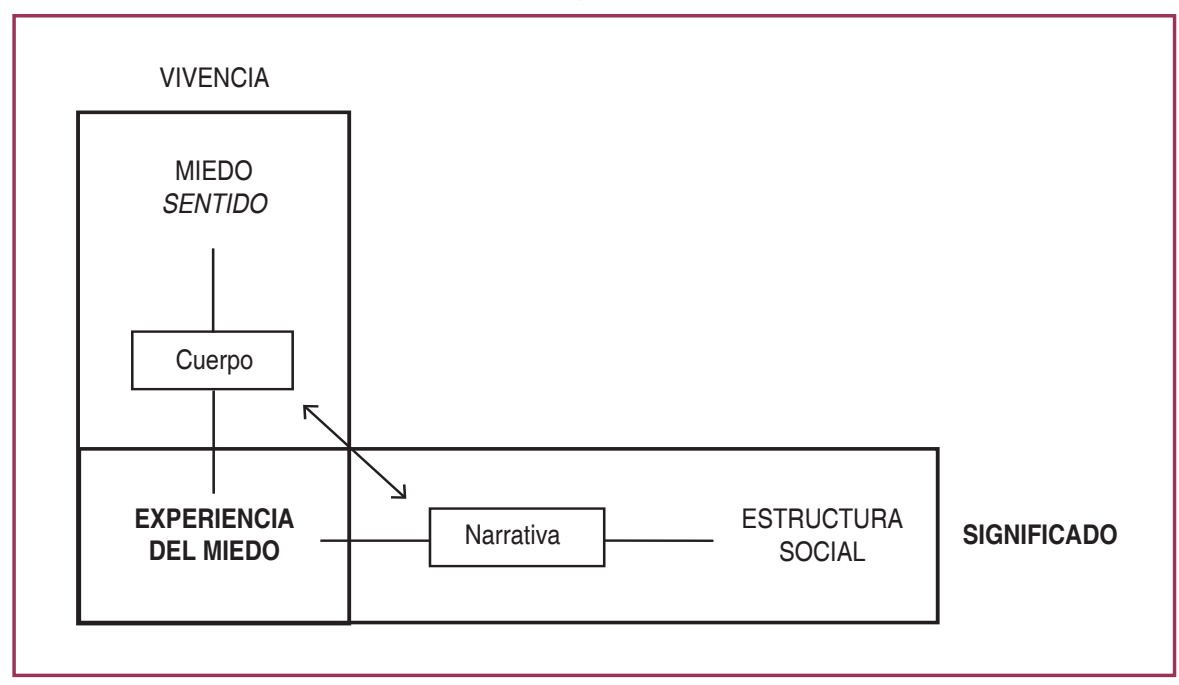

Fuente: los autores

La línea vertical que atraviesa el cuerpo representa la vivencia orgánica del miedo, el miedo real, el cual se circunscribe al cuerpo biológico de la persona que lo siente. Se trata de 
algo inconmensurable e inefable que 'escapa al saber en tanto es vivido por uno a pesar del conocimiento' (PIGLIA, 2015, p.141). La línea horizontal que atraviesa la narrativa representa el significado construido del miedo, y hace referencia su carácter performativo: el miedo se hace y cobra sentido en el momento en que se narra. Ese proceso narrativo mediante el cual se construye el significado del miedo está enmarcado por estructuras y convenciones situadas en contextos culturales, políticos e históricos determinados. Al encontrarse, las líneas de la vivencia y del significado conforman la experiencia del miedo, implicándose y retroalimentándose mutuamente.

El cuerpo, la narrativa y la experiencia de miedo conforman un triángulo sistémico. La flecha que une los vértices cuerpo y narrativa simboliza a la vez una sinergia y una tensión. La sinergia se produce porque el cuerpo es 'simultáneamente causa, tema e instrumento de cualquier historia' (SPARKES; SMITH, 2011, p.359). El cuerpo que siente miedo se hace reconocible al contar historias. Al escuchar una historia, escuchamos al cuerpo hablando en ella (FRANK, 2013). Por tanto, las historias permiten 'contar el miedo' del cuerpo. La tensión se debe a la diferencia fundamental entre la experiencia orgánica del miedo y cualquier representación narrativa de esa experiencia (CARLESS; DOUGLAS, 2016). La narrativa y el miedo establecen una conexión de segundo orden: el miedo es demasiado real para contarse hablando.

La vivencia (el miedo sentido) y el significado (el miedo narrado) resultan inseparables. Por tanto, no basta con reducir la experiencia de miedo al contenido de una historia y más tarde analizar dicho contenido, ya que el miedo es incapaz de significar algo fuera del cuerpo que lo vive. Si queremos acceder a la experiencia de miedo no podemos conformarnos con registrar y catalogar declaraciones explícitas, sino que también debemos atender las formas en que el miedo se articula en el cuerpo, implícitamente y a través de interacciones sociales (KUBY, 2014; TAMMINEN; BENNETT, 2016). Por lo tanto, el miedo no puede compartirse ni entenderse sin lo que Carless y Douglas (2016, p.55) denominan una 'inmersión interactiva corporeizada' en el contexto de su vivencia.

\section{CONTEXTO, PROCEDIMIENTO Y MÉTODO}

El estudio se ubica en un instituto de enseñanza secundaria español. Javier participó en el centro dos meses, ejerciendo funciones de profesor en prácticas durante veintidós horas semanales. Su horario se adaptaba al de Felipe ${ }^{1}$, profesor de EF. Las clases que Felipe tenía asignadas abarcaban todos los niveles educativos, desde primero de E.S.O. hasta segundo de Bachillerato. Debido al convenio de sus prácticas docentes, Javier debía desenvolverse en la función de profesor y desempeñar labores pedagógicas. Felipe ejercía el papel de tutor.

Albergar la triple condición de estudiante en prácticas, profesor e investigador planteaba dilemas e incompatibilidades. Por ejemplo, mediar en una discusión entre dos alumnos (rol de profesor) entraba en conflicto con el principio de abstenerse de emitir juicios sobre las conductas del alumnado (rol de investigador) y de reprochar las soluciones que Felipe ofrecía como profesor a esa contingencia (rol de estudiante). No obstante, ocupar esta triple posición también suponía una importante ventaja estratégica en la medida en que facilitaba el acceso a distintos ambientes y participantes en calidad de igual, configurando así una visión polifónica de las mismas realidades vividas por los distintos agentes.

A raíz de varios sucesos en los que se vio implicado, Javier tomó conciencia de que el miedo constituía un componente esencial en las vivencias más negativas del alumnado de EF

1 Todos los nombres propios de las personas participantes son pseudónimos 
más vulnerable. Por ello, decidió centrarse en recoger datos sobre este fenómeno. El proceso de obtención de datos se ajustó a las eventualidades del día a día y las posibilidades de acción que le permitía cada escenario. En consecuencia, la fuente de datos fue ecléctica, variada y adaptativa. En cuanto a las técnicas de recogida de datos, destacó la observación participante. Dentro de esta práctica, las conversaciones abiertas y desestructuradas resultaron clave, ya que dieron lugar a historias pequeñas: narrativas fugaces que emergen en tiempo real, en los diálogos que se consuman en escenarios cotidianos (GRIFFIN; PHOENIX, 2016). Las historias pequeñas están situadas en la interacción social, de modo que es importante tomarlas en cuenta, puesto que ofrecen proximidad a las experiencias vividas de los participantes.

Esta proximidad convierte al proceso de investigación en una tarea emocional. De acuerdo con Alneu et al. (2016), el cuerpo, las emociones y el conocimiento tácito del investigador puede ser un instrumento para captar y entender la interacción social en la que se inserta el miedo. Por tal motivo, las emociones del investigador resultaron un parámetro fundamental respecto a la experiencia del miedo en EF. La implicación de Javier y el componente emocional de la investigación demandaba la participación de un amigo crítico que aportara una mirada externa, más analítica y serena, que equilibrara el proceso de investigación. A raíz de la colaboración con Víctor emergieron una serie de preocupaciones, de entre las que, por limitaciones de espacio, priorizamos el referirnos a las cuestiones éticas.

Al igual que Frank (2011, p.157), entendemos la ética como una práctica esencialmente procesual y dilemática, en la que los apriorismos juegan un papel limitado. Cuando se asume que la ética emerge en diálogo con la realidad estudiada, las historias cobran protagonismo como "recursos y medios con y a través de los que se sirven las personas para descubrir lo que cuenta como correcto". Dicho de otro modo, el estatus ético de las historias depende del grado en que contarlas y escucharlas contribuya a hacerlas reconocibles y a clarificar lo que es correcto. Con todo, esta necesidad de proporcionar claridad resulta necesariamente controvertida. Para dar respuesta adecuada a la obligación y la responsabilidad moral que sentíamos en relación con las historias, decidimos adoptar dos estrategias básicas.

La primera, dirigida a la protección de las personas participantes, consistió en usar seudónimos, alterar lugares y tiempos y descartar aquellas historias que pudieran comprometer y perjudicar a determinados participantes por motivos diversos. Asimismo, procuramos utilizar un lenguaje que mantuviera un adecuado equilibrio entre el compromiso de reflejar lo vivido y la responsabilidad de no herir a los actores implicados en el estudio. La segunda estrategia guarda relación con la postura adoptada para analizar, interpretar y (re)presentar los resultados, y no sólo responde a preocupaciones éticas, sino también a intereses prácticos, epistemológicos y estéticos. En este plano, decidimos adoptar el papel de investigador como narrador de historias (PÉREZ-SAMANIEGO et al., 2011). El investigador narrador se sitúa como un testigo modesto del fenómeno de estudio (HARAWAY, 1997). En contraste con el investigador analista, el narrador considera que explorar la experiencia no supone diseccionarla y categorizarla, sino respetar la historia que nos cuenta, sin simplificarla ni finalizarla, intentando captar la complejidad de los sucesos tal como se presentan. De esta manera, el investigador narrador se sitúa en y no contra la complejidad de las historias.

La forma de poner en práctica esta postura consistió en utilizar prácticas analíticas creativas (PAC) (RICHARDSON, 2000). Las PAC buscan integrar los 'Qué' (qué se cuenta en las historias) y los 'Cómo' (la manera en que esas historias se construyen y contextualizan) 
combinando recursos creativos de escritura y métodos analíticos. Nuestro acercamiento específico a las PAC se mueve en un espectro situado entre la etnografía no-ficción creativa y la ficción creativa (SPARKES; SMITH, 2014). La etnografía no-ficción creativa nos permite dar cuenta de los hechos observados, incorporando las observaciones y las voces de las personas participantes en el conjunto de un relato. La ficción creativa facilita acceder, a través de la imaginación, a determinados ambientes narrativos distantes, inaccesibles 0 invisibles, pero pertinentes para mostrar y comprender lo que sucede en torno al miedo. La preocupación por el componente estético y evocativo del lenguaje, común a ambos géneros, expande la posibilidad de entender el miedo no como (supuestamente) es, sino como es vivido.

\section{RESULTADOS}

A continuación, presentamos una serie de escenas que evocan experiencias del miedo en EF.

\section{Eva: una introducción}

Son las 6 a.m. Me despierta un sentimiento de fatalidad. Hundo la cara contra la almohada y me cubro entera con el edredón. Hoy hay examen de voleibol. Resulta difícil encontrar un motivo peor para salir de la cama.

Me levanto, me visto, me pongo las gafas y abro la bolsa de deporte para un último recuento. Compruebo lo que contiene sin prestar mucha atención: ya van tres veces. Vuelvo a colocar todo a presión. La ropa no cabe. La bolsa parece haber empequeñecido, y cuesta cerrar la cremallera. Ciérrate, por el amor de Dios.

La casa está en silencio. Empiezo a pasearme por la habitación. No entra luz por las ranuras de la persiana. Me paseo como un animal enjaulado por la habitación oscura. Son las $6: 15$.

Las ocho

Entro en la cocina. Me siento en la mesa. Sergio está bebiendo un zumo. Mamá prepara el desayuno y mi padre lee algo en el IPad, las noticias, supongo.

- ¿Has dormido bien? - pregunta mi madre.

Digo que sí. Lo cierto es que no he conseguido descansar en toda la semana.

- Mejor prepárame una tila - digo.

Mi madre deja un cuenco de cereales en mi sitio y dice que una tila no es un desayuno.

- Si estás tranquila y tienes confianza te saldrá bien - dice. Esboza una sonrisa mitad comprensiva, mitad grotesca.

- Vale mamá.

- No hay por qué preocuparse. Has estado practicando -dice mi madre, y vierte café en la taza de papá.

- Sí - dice Sergio -. Un diez, vas a sacar. Apuesto a que sí. 
Desde que tengo memoria, Sergio me ha fastidiado como sólo un hermano mayor puede hacerlo. Tengo catorce años y él tiene dieciséis. Fuimos a la misma escuela y vamos al mismo instituto.

Nuestra madre siempre dice que debemos esforzarnos por conseguir las mejores notas. De lo contrario, no podremos aspirar a algo más de lo que han conseguido ella y papá. Algunos llegan a la cima, otros van al fondo, así funciona. En EF, Sergio está en la cima, yo estoy en el fondo. Mis aspiraciones en EF se reducen a no tropezar y romperme las gafas, 0 la cabeza, y no hacer demasiado el ridículo. Suspender la asignatura es de todos los ridículos el mayor. De toda la vida, si suspendes gimnasia estás en la mierda. De manera que debo cuidarme de aprobar hoy el examen...

Le pido a Sergio que me pase la leche. Me la deja lo suficientemente cerca para que crea que puedo cogerla y lo bastante lejos para que tenga levantarme, y mientras vuelco la leche en el cuenco de los cereales me deja claro que voy a catear el examen.

Te he visto jugar a vóley, dice. Si yo fuera Felipe, hoy te suspendía, dice. También dice que lo único que quiere Felipe, el profesor de EF, es dar la clase con normalidad, y que las chicas nos dejemos de tonterías y movamos el culo.

Yo le digo que se calle.

- En mi clase, cuando jugamos al fútbol o a cualquier deporte de verdad, siempre pasa lo mismo - insiste él -. Las chicas siempre están quejándose. Como no dais ni una y suspendéis el examen os picáis con Felipe y decís que es un machista. A veces la cosa se le va de las manos, pero no es su culpa: es vuestra.

- No quiero oírte, Sergio, tío - insisto yo.

- Si lo haces bien apruebas. Si lo haces mal, suspendes; es lo justo ¿no? Si ni si quiera sabéis las reglas...

- ¡Cierra la boca! - le grito.

- Me la vas a cerrar tú.

Entonces echo atrás la silla para levantarme. De nerviosa y saturada que estoy. Siempre igual. Da lo mismo las veces que me lo haga. Siempre caigo. Esta vez no puedo soportarlo. Los dedos se aferran la mesa y me pongo de pie. Entonces mi padre levanta la mirada irritada del IPad y dice:

- Queréis callar los dos.

Luego dice que no sea tan exagerada y que me siente con la familia a desayunar.

\section{En el recreo}

Es la hora del recreo. La cafetería está de bote en bote, de modo que nos sentamos fuera en el patio, en las escaleras. Enfrente de nosotras unos niños juegan al fútbol con un cartón de zumo espachurrado. El cielo palidece. Hace fresco, llevamos bufanda.

Estoy con mis amigas. Hablan unas con otras, pero me cuesta mucho trabajo enterarme de lo que dicen. Un pensamiento disperso anula mi capacidad para concentrarme 
en la conversación. Puede pasar medio minuto sin que piense en nada, sin saber siquiera que existo, y entonces, de sopetón, aparece nítida la imagen del gimnasio en mi cabeza. Hago memoria de las clases pasadas, repaso errores, imagino en qué consistirá el examen; ahora elaboro jugadas perfectas, fantaseo con ejecutar movimientos eficaces y elegantes; yo soy la que marco los tantos y me llevo las felicitaciones de los compañeros. ¡Qué Crack, Eva! ¡Lo has petado!, me dicen, y Felipe aplaude orgulloso.

Hago ademán de mirar la hora y cuando quiero darme cuenta tengo las manos pegadas entre los muslos, los pulgares sobre los índices, colocados en una posición antinatural, la posición de recepción en voleibol. Separo las manos enseguida, como si quemaran. Creo que no me ha visto nadie.

En ese momento Elisa me pregunta algo, pero no la oigo.

- ¿Qué? -digo.

- Estás callada.

- Estoy bien -digo, cuando en realidad no me siento nada bien.

Elisa detesta a Felipe tanto o quizá más que yo. Mis amigas y yo lo ponemos a parir. Hay algo inquietante en su cara que no sé explicar y que me eriza los vellos de la nuca. Nunca sabes por dónde va a salirte. No sabemos interpretarlo ni hacer las cosas como a él le gustan. Nos echa la bronca por cualquier tontería y acto seguido nos suelta el rollo. Su trabajo es enderezarnos, dice, necesitamos algo así, una mezcla de disciplina y cariño, lo llama. Y una mierda cariño. Nos transmite la sensación de que todo lo vas a hacer mal, hagas lo que hagas. En estas condiciones, lo hacemos mal y sin ganas.

Alguien me toca el hombro.

- ¿Estás bien? -pregunta Carlos.

No lo había visto. Debía de haberse acercado en ese mismo momento.

- Está preocupada por el examen -interviene Elisa- ¿Verdad que es eso Eva?

Que lo diga me gusta y me disgusta a la vez.

- No pasa nada- dice Carlos. El trimestre que viene toca bailar. Te irá mejor entonces.

- Supongo-digo yo.

Carlos se queda mirándome, como aguardando a que haga algo.

¿Por qué me mira asi?? ¿A qué espera?

Yo le sonrío con amabilidad. Parece satisfecho. Vete, pienso, pero no digo nada. Como no digo nada, se vuelve para hablar con Elisa.

No hay nada que hacer, sólo esperar. En escasos minutos, el instituto nos absorberá como una aspiradora. Iremos a contracorriente, hacia el gimnasio, cruzándonos con todo el mundo por el camino. Suena la canción que comunica que el recreo ha terminado.

\footnotetext{
Y se formó la gozadera, Miami me lo confirmó

Y el arroz con habichuela, Puerto Rico me lo regaló

Y la tambora merenguera, Dominicana ya repicó

Con México, Colombia y Venezuela y del Caribe somos tú y yo

¡Repicando!
} 


\section{La Soldado}

Antes tenía miedo de recibir un balonazo, me confesó Ana María una mañana. La cabeza ladeada, se peinaba con dificultad la melena larga con los dedos. Siempre ha sido muy guapa. Recuerdo que aquella mañana salimos del vestuario con el pelo empapado y que prácticamente corríamos por los pasillos para no llegar demasiado tarde a la siguiente clase. Me curé de ese miedo gracias a una profesora que tuve en sexto de primaria, dijo Ana María tras darse un tiempo para recordar. La llamábamos La Soldado, dijo por fin, y tenía la costumbre de darnos un pelotazo cada vez que nos veía con miedo. Algo le hizo gracia y sonrió. Luego prosiguió seria: nos daba buenos pelotazos. Era muy bestia, hay que reconocerlo. Pero así nos enseñó que no era para tanto, al fin y al cabo. No había por qué tener miedo, me dijo Ana María, la pelota no iba a hacernos daño, o muy poco.

La Soldado. Caray. Pero hubiera estado bien tenerla de profesora. Quiero decir que preferiría haber recibido esos pelotazos entonces, y no tener miedo a estas alturas. Haber pasado por eso de pequeña y ya está, como cuando pasas la varicela. Es mucho peor ahora. Suelo pensar en ello bastante. Definitivamente, haber tenido a La Soldado habría sido lo mejor. Gracias a ella, Ana María se hizo fuerte. Se convenció, por así decirlo, de que no debería afectarle tanto, pues aun cuando tuviera miedo podría encajarlo y salir adelante. Sabía que en el fondo no pasaba nada. Yo también lo sé, pero una cosa es saberlo y otra bien distinta sentirlo.

\section{Voluntaria}

La semana pasada, Felipe me tomó como 'voluntaria' para explicar la recepción del balón tras el saque. Suele escoger a alguien a fin de mostrar a la clase cómo debe y cómo no debe hacerse cierta técnica. Normalmente me escondo detrás de todos para que no me elija a mí. Debí despistarme aquella mañana, porque me señaló con el dedo. El corazón me dio un vuelco cuando me señaló. Ven aquí, mujer, me dijo. Ponte aquí. Ponte aquí, mujer, y dale a la pelota. El silencio que se creó mientras me coloqué donde me dijo me oprimió un poco el pecho.

Mientras Felipe describía la técnica de recepción, 'hay que poner las manos así, hay que poner las piernas asá'..., vamos, lo de siempre, yo me di unas palabras de aliento; me dije a mí misma que esta vez sí. Estaba decidida a impresionar a todos y devolver todas las bolas.

Qué ilusa.

Después de varios errores y ningún indicio de que la cosa fuera a mejorar, se empezó a formar un hueco incómodo en mi presencia que se hacía más grande cada segundo, eclipsando todo lo demás. Sentía la mirada de mis compañeros ardiéndome en la piel, sentía que nunca podría escaparme de sus miradas. El balón es una amenaza concreta y física, pero que te observen es algo abstracto, no se puede controlar de la misma forma. Es horrible estar de culo a todo el mundo mientras haces el ridículo. Es mucho peor que exponer un Power Point en clase de biología.

Al final, Felipe resopló enfadado y llamó a Vicente para que me sustituyera. Le lanzó la pelota siete u ocho veces y Vicente las devolvió todas, la pelota iba a parar donde quería que fuera a parar. Así es como se hace, dijo Felipe abriendo los brazos. Luego me miró arrogante, como dándome una lección. 


\title{
Suspense/-0
}

La luz eléctrica parpadea mientras me cambio. Levanto los brazos para quitarme el jersey. Hay 15 chicas aquí. La pared de cerámica blanca brilla. Está helada: un escalofrío me recorre cuando me roza la espalda desnuda; me aparto en un acto reflejo, luego la sudadera ancha se deja caer.

De repente me asalta en el estómago la presión de demostrar a todo el mundo que puedo conseguirlo. Me entran unas ganas terribles de ir al baño. Me pongo el pantalón y las deportivas lo más deprisa que el sigilo me permite (no quiero levantar sospechas) y entrecierro la puerta del vestuario al salir.

Entro en el último cubículo del baño y cierro el pestillo. Levanto la tapa del váter y me agacho. Por dentro, la puertita del meadero está llena de números de teléfono, insultos y símbolos y penes dibujados. Mientras termino, hago trocitos con el papel higiénico; eso me distrae, eso me calma.

Tiro de la cadena y me sitúo frente al espejo. Debajo del espejo hay tres piletas acopladas a una encimera de mármol. Con cuidado, dejo las gafas sobre la encimera y, con un golpe de muñeca, abro un grifo. Echo un trago. El agua sabe al tufo del servicio, ya lo sabía, pero había de beber de todos modos, porque tengo la boca pastosa. Mientras me seco la boca me encuentro con mi reflejo borroso en el espejo. Me pongo las gafas. Aquí estoy, delante de mí, y lo que veo no me transmite ninguna confianza. No creo que pueda aprobar el examen. Puedo hacerlo bien, pero no estoy preparada para ello. Tranquila, tranquila, me repito en mis adentros. Tampoco es que esto sea el fin del mundo. No. No, no es el fin del mundo. Mañana será otro día. Y sin embargo...

Salimos del vestuario y nos sentamos en el suelo azul plastificado.

- Levantad-dice Felipe-. Vosotros dos, sacad el carrito.

Mientras tanto dos de mis compañeros van al almacén, él coloca las redes de voleibol. En realidad, no son redes, sino cintas de plástico, a rayas diagonales, tipo el cordón policial que protege el escenario de un crimen, que Felipe engancha a las espalderas y a dos postes blancos de voleibol. En el carrito, los balones de cuero se amontonan uno sobre otro. Todos se abalanzan para coger los buenos. Ahora calentamos a nuestro aire. Me paso el balón con Elisa sin mantener contacto visual. BAM! BAM! A nuestro alrededor, los balones vuelan bajo. Finalmente, Felipe nos reúne al centro del pabellón.

\begin{abstract}
Lo tenemos claro ¿no? Equipos de seis y hacemos el sorteo de qué dos equipos juegan primero. Quien se quede sin grupo jugará luego, con gente que haya hecho el examen ya. Vosotros sabréis con quién os ponéis. Ya lo he dicho mil veces, y quien avisa no es traidor. Luego no vengáis a quejaros de que habéis suspendido por culpa de fulanita... ehh... el voleibol es un juego colectivo. Se puntúa por equipos. En el examen, si un equipo consigue hacer tres toques y pasar el balón al campo contrario suma un punto. Si no lo consigue, lo resta. Os doy 25 jugadas. 12 puntos es un 5 . Si no aprobáis es para mataros. Va, va, los equipos, ya, no tenemos tiempo.
\end{abstract}

El examen da comienzo con un silbido.

Primero juega el equipo 1 contra el 4. Yo estoy en el equipo 2, así que estoy sentada en un banco sueco, esperando. En el equipo 1 sólo hay chicos, en el 4 está Rubén, por suerte para ellas. 
Vicente va sobrado, esprintando y frenando sobre las puntas de los pies, peinándose el pelo. Mirando de reojo. Remangándose los pantalones cortos. Pasando la pelota sin mirar. Sonriendo con media boca. ¿Has visto qué mate? Tírala alta. ¡Qué buena, joder! Abre las piernas y parece un puñetero jugador de voleibol. Al menos al lado de Héctor lo parece. Abarca el gimnasio entero, haciendo que los demás parezcan pequeños. Tiene lo que Felipe llama 'talento deportivo innato'. Héctor no lo tiene. Intenta hacer lo que Vicente, pero no se puede mantener la torpeza en secreto. Los tipos como Héctor siempre corren como unos locos a chocar la mano a los tipos como Vicente. Bueno, no sé, a veces hacemos cosas para ocultar que no podemos hacer esas cosas.

En un pálpito, busco a Felipe con la mirada. Se pasea tranquilo por la línea de banda, las manos cruzadas por detrás de la espalda. Baja la vista y anota algo en la libreta de forma indiferente. Aparto la vista y paseo la mirada por el gimnasio hasta que, de golpe, algo detiene mi atención en Carmen.

Carmen. Del equipo 4. La miro jugar.

Se frota los párpados y a menudo le falta el aliento.

Sus movimientos son lentos y torpes.

Siempre da la impresión de estar donde no debe estar.

Yo sigo observándola. Nunca hasta ahora me había fijado en cómo juega. Entre punto y punto, retuerce la punta de la zapatilla contra el piso y mira a un lado y a otro sin saber muy bien dónde colocarse. Se nota que pone su mejor voluntad.

¿Tengo yo el mismo aspecto cuando juego al voleibol?

Seguro que sí.

Lejos de consolarme por no ser la única, verla así me pone más tensa. Con un golpe seco, cualquiera podría partirme como a una barra de pan congelado.

Saca Vicente. La pelota supera la red y cruza hacia otro campo como un misil. Se dirige hacia Carmen, pero ella no la ve venir hacia su posición. ¡Carmen!, le gritan, y ella se endereza en un espasmo. Cuando por fin la ve venir se encoge cual tortuga, llevándose ambas manos a la cabeza para defenderse y apartándose de en medio con un saltito... y la pelota cae al suelo, rebota y rueda y se detiene.

- ¡Me cago en la leche! -grita Felipe, y cierra su libreta.

Durante un segundo escondo la cara bajo la bufanda, como para tapar la realidad. Pero no puedo evitar mirar. En el fondo, la situación me provoca morbo. En un movimiento involuntario aparto la vista, como si necesitara coger fuerzas para volver a mirar. A mi alrededor oigo risitas, risotadas, silencios. Felipe se acerca a Carmen a zancadas, con los cordones de las zapatillas desatados, como siempre. Se detiene junto a ella y dice:

- ¡Las rodillas flexionadas, Carmen, joder! ¿Me estás tomando el pelo? propósito?

¿Cómo no se da cuenta de que ella no quería apartarse, de que no lo había hecho a

Ella se hunde las manos en los bolsillos de la sudadera.

- Quítate las manos de los bolsillos -dice Felipe. 
Carmen saca las manos que cuelgan de los brazos.

- Dime: ¿cuántas veces he dicho que las rodillas siempre van flexionadas? Siempre lexionadas, siempre flexionadas, siempre flexionadas, fle-xio-na-das, fle-xio-na-das. Parezco un disco rayado ¿Cuántas veces lo he dicho, Carmen, princesa?

Silencio.

Ahí está Carmen, inmóvil, conteniendo su agitación, la vista fija en Felipe. Apenas se atreve a parpadear por temor a que suceda algo. Aguanta y traga saliva.

Perdón, dice, y emite una risita nerviosa.

Felipe se da la vuelta para ocultar una mueca de desdén.

Carmen, por su parte, vuelve la cabeza para mirar de soslayo a la pelota que ha vuelto a manos de Vicente. Y se prepara de nuevo para intentar recibir su saque.

Quedan dos puntos para que Carmen termine su examen y empiece el mío. La veo y mi rodilla se me mueve arriba y abajo a toda velocidad. Carmen, la veo con mis propios ojos, casi llora de rabia y frustración. Parece a punto de abandonar, aniquilada. Pero sigue allí, de pie, jugando a voleibol, roja como un tomate.

\section{REFLEXIONES FINALES}

Las escenas anteriores se presentan como una 'historia reconocible' (BAERGER; MCADAMS, 1999), representativa del miedo que parte del alumnado siente hacia y en la EF. En comparación con las formas tradicionales de representación, escribir escenas permite condensar y congelar las realidades cotidianas del contexto estudiado, ilustrando su complejidad. Esta forma de representación de los resultados resulta particularmente adecuada para trasladar experiencias al lector de manera abierta, evocativa, emocional y corporeizada (SPARKES, 2009).

Cuando se trabaja con formas creativas de investigación, a menudo se renuncia a diseccionar analíticamente el producto, proponiendo únicamente una lectura empática, estética y personal (SMITH et al., 2013). Valoramos y estimamos provechosa esa forma de acceso abierto y participativo a los significados del relato, y quién se sienta satisfecho con ella puede finalizar aquí la lectura del artículo e iniciar su propio diálogo con las escenas. No obstante, hay que tener en cuenta que una historia, por sí misma, no siempre es capaz de estimular una reflexión crítica sobre los temas que trata (FRANK, 2010). De ahí que también merezca la pena ofrecer espacios para que el lector piense sobre las escenas, y qué pueden aportar éstas para progresar en el conocimiento teórico y práctico acerca de cómo el miedo opera y es experimentado en la escuela.

Entre los muchos conceptos que pueden proporcionar resonancia teórica a las escenas, resultan particularmente productivos los de habitus y violencia simbólica (BOURDIEU, 1990, 2001). El habitus es la forma en que las estructuras sociales se inscriben en el cuerpo. Puede definirse como una serie de disposiciones incorporadas e irreflexivas que inclinan a las personas hacia intenciones y prácticas particulares en contextos socio-culturales dados. A partir de este concepto, Frank (2010) propone la noción de habitus narrativo para referirse a la colección de historias que interpelan a las personas, creando un sentimiento de atracción, indiferencia o 
rechazo en respuesta a determinadas historias. El habitus narrativo subraya la íntima relación existente entre la vivencia corporal, las estructuras sociales, las narrativas y las relaciones de poder, en este caso, en relación con la experiencia del miedo (véase figura 1). Cuando esas relaciones de poder inscritas en la experiencia se presentan como naturales y evidentes, dan pie a lo que Bourdieu (2001) denomina violencia simbólica. Este tipo de violencia tiene lugar cuando las relaciones de poder se somatizan y se toman por algo irrefutable, provocando que las personas que ocupan las posiciones dominadas reproduzcan las categorías de percepción y valoración que son la condición de su dominación. Las víctimas, pues, se convierten en cómplices de la dominación a la que están sometidas. Se trata de una violencia articulada en términos invisibles, amortiguada, porque se apoya en la complicidad muda del propio cuerpo. En el caso que nos ocupa, se produce violencia simbólica en el momento en que Eva se hace responsable individualmente de su miedo sin tener en cuenta las estructuras sociales que lo dotan de significado.

El habitus narrativo y la violencia simbólica están presentes de forma implícita en la experiencia del miedo que evocan las escenas. En este sentido, la elección de Eva como narradora y caso representativo no es casual. A través de su mirada, la EF se presenta como un territorio de relaciones normativas de poder que conforma subjetividades de género productoras de desigualdad. Esta mirada incorpora sistemas de creencias como la heteronormatividad (SHARMA, 2009) o la masculinidad hegemónica (VIDIELLA et al. 2010), los cuales provocan que en muchas ocasiones las chicas sean concebidas y tratadas como seres esencialmente emocionales, débiles y vulnerables, mientras que los chicos lo sean como seres racionales, agresivos y capaces. En el contexto particular del relato, las condiciones estructurales, los ambientes narrativos y la autoridad de las figuras masculinas potencian la aparición y el mantenimiento del miedo. Con ello no afirmamos que el miedo en y a la EF sea privativo de las alumnas, o de determinadas alumnas. Obviamente, muchos alumnos sienten miedos, similares o distintos al que puedan sentir algunas alumnas. Con todo, merece la pena concienciarse de que las estructuras y sistemas de creencias patriarcales de género en EF predisponen, aceleran y propagan el miedo, convirtiéndolo en una emoción colectiva que se contagia entre las personas perjudicadas por dichos sistemas (TAMMINEN et al., 2016).

En relación con las asunciones esencialistas y funcionalistas acerca del género, el miedo que hemos relatado cobra vida y sentido a través de un enfoque meritocrático, pragmático y deportivo de enseñanza (LARSSON et al., 2009). Las responsabilidades individuales asumidas por Eva ejemplifican cómo este enfoque pedagógico se alinea con el proyecto social neoliberal. En línea con Putwain (2009), las escenas presentadas en el relato identifican tres fuentes de presión social en relación con el miedo: el propio alumnado, el profesor y los padres. Esas presiones provienen del miedo al fracaso dentro del seno de las familias de clase media, como la de Eva. La gran mayoría del alumnado teme el fracaso académico y social (JACKSON, 2010). El miedo al fracaso y la coacción al rendimiento afectan por igual a chicas y a chicos, si bien las chicas tienen más miedo a los exámenes (PUTWAIN, 2009). Según plantea Jackson (2010), esto se debe a que las chicas están más dispuestas a hablar sobre la experiencia del miedo; lo cual puede ser un reflejo de las construcciones hegemónicas de la masculinidad (VIDIELLA et al., 2010). En todo caso, hablar sobre ciertos miedos puede marcar a las chicas (no a todas, y también a algunos chicos) como sujetos neoliberales fracasados (JACKSON, 2010). 
Con este trabajo, pretendemos situar el miedo en un ángulo de comprensión que estimule, en última instancia, a actuar. En este sentido, la pregunta que surge es ¿qué podemos y qué debemos hacer (y qué no) con respecto al miedo en EF? Tal interrogante lleva implícito una componente moral. Lo primero que hay que aclarar es que el miedo, como cualquier otra emoción, no puede ni debe ser eliminado de la experiencia educativa. El miedo puede protegernos de situaciones amenazantes. Además, en ocasiones puede contribuir al aprendizaje de aquellas personas que disponen de recursos y opciones para superarlo (PUTWAIN; REMEDIOS; SYMES, 2015). Pero es preciso tener en cuenta que la capacidad de las personas para superar el miedo viene condicionada en gran parte por sus habitus narrativos. La afinidad selectiva sentida hacia ciertas historias que dan significado al miedo en EF traslada las inequidades sociales de poder a la vivencia corporal. En determinadas circunstancias, algunos habitus narrativos favorecen a unas personas y perjudican a otras. Obviar este hecho es una forma de violencia simbólica, en la medida en que culpabiliza a las propias personas que sienten miedo.

Por tanto, las cuestiones a clarificar moralmente son: ¿quién siente miedo en EF?, ¿cómo lo siente?, ¿quién lo provoca y porqué?, ¿cuáles son sus fuentes?, ¿cómo se produce?, ¿qué efectos tiene? y, sobre todo, ¿a quién beneficia y quién perjudica el miedo? Dar respuesta moral a estas cuestiones entraña compartir historias que las hagan visibles y faciliten el diálogo en torno ellas. Como afirma Frank (2011), las historias hacen la vida moral posible. Un enfoque narrativo del miedo, por ejemplo, abre una puerta para pensar en las historias como espacios productivos de empoderamiento. Concretamente, el relato que hemos presentado puede ayudar a comprender y sentir que existen motivos para temer la EF. A partir de esa toma de conciencia, pueden activarse distintos mecanismos orientados a ampliar el repertorio de historias posibles que ayuden a crear espacios de poder y contrapoder. Difícilmente ese proceso puede activarse por quienes sienten y hacen sentir miedo, precisamente porque sus habitus narrativos prueban ser de poco valor para clarificar moralmente el miedo. Clarificar el miedo exige interlocución y diálogo con otras personas que nos ayuden a encontrar historias que encajen, aquellas en las que "las personas descubren cuáles son sus valores, a medida que atraviesan ese extraño terreno en el que los puntos de referencia anteriores parecen tener poca utilidad como guía" (FRANK, 2011, p.159).

Frank (2010) propone el concepto de emboscada narrativa para referirse al proceso mediante el cual unas personas tratan de ampliar el repertorio narrativo de otras. Todos los agentes educativos pueden verse implicados y participar, de algún modo, en emboscadas narrativas que ayuden a resignificar la experiencia del miedo en EF. Ahora bien, como en cualquier cambio educativo real, el profesorado cobra un papel central en este proceso. Si bien el profesorado no puede actuar directamente sobre el miedo real que siente el alumnado, sí puede tratar de trasformar las estructuras sociales y narrativas que le dotan de significado en la práctica educativa. Desde esta visión, ampliar el repertorio de historias que permitan al profesorado reconocer el miedo como un componente de sus prácticas pedagógicas puede ayudar a generar una comprensión más profunda y sensible de la acción docente. La historia que hemos presentado aspira a contribuir, modestamente, a este propósito. 


\section{REFERENCIAS}

ALNEU, Sharyn et al. Observing judicial work and emotions: using two researchers. Qualitative Research, v.16, n.4, p.375-391, Aug. 2016.

BAERGER, Dana; MCADAMS, Dan. Life Story Coherence and its Relation to Psychological Well-Being. Narrative Inquiry, v.9, n.1, p.69-96, 1999.

BOURDIEU, Pierre. The logic of practice. Cambridge: Polity, 1990.

BOURDIEU, Pierre. Masculine domination. Stanford: Stanford University, 2001.

BOURKE, Joanna. Fear: A cultural history. London: Virago, 2015.

CARLESS, David; DOUGLAS, Kitrina. Narrating embodied experience: sharing stories of trauma and recovery. Sport, Education and Society, v.21, n.1, p.47-61, 2016.

FRANK, Arthur. Letting stories breathe. Chicago: The University of Chicago, 2010.

FRANK, Arthur. The Philosopher as Ethicist, the Ethicist as Storyteller. In: WIGGINS, Osborne; ALLEN, Annette. Clinical Ethics and the Necessity of Stories: Essays in Honor of Richard M. Zaner. Netherlands: Springer, 2011. p.153-163.

FRANK, Arthur. The wounded storyteller. Chicago: The University of Chicago, 2013.

GRIFFIN, Meredith; PHOENIX, Cassandra. Becoming a runner: big, middle and small stories about physical activity participation in later life. Sport, Education and Society, v.21, n.1, p.1127, 2016

HARAWAY, Donna. Modest_Witness@second_Millenium. Female-Man@_meets_Onco Mouse $^{\mathrm{TM}}$. Feminism and Technoscience. New York: Routlegde, 1997.

JACKSON, Carolyn. Fear in education. Educational review, v.62, n.1, p.39-52, Apr. 2010.

KUBY, Candace. Understanding emotions as situated, embodied, and fissured: thinking with theory to create an analytical tool. International Journal of Qualitative Studies in Education, v.27, n.10, p.1285-1311, 2014.

LARSSON, Håkan; FAGRELL, Birgitta; REDELIUS, Karin. Queering physical education. Between benevolence towards girls and a tribute to masculinity. Physical Education and Sport Pedagogy, v.14, n.1, p.1-17, Jan. 2009.

MCNAY, Lois. Agency and experience: Gender as a lived relation. The Sociological Review, v.52, n.S2, p.173-190, oct. 2004.

PÉREZ-SAMANIEGO, Víctor; FUENTES, Jorge; DEVÍS-DEVÍS, José. El análisis narrativo en la educación física y el deporte. Movimento, v.17, n.4, p.11-42, out./dez. 2011.

PIGLIA, Ricardo. Los diarios de Emilio Renzi: Años de Formación. Barcelona: Anagrama, 2015.

PUTWAIN, David. Assessment and examination stress in Key Stage 4. British Educational Research Journal, v.35, n.3, p.391-411, 2009. 
PUTWAIN, David; REMEDIOS, Richard; SYMES, Wendy. Experiencing fear appeals as a challenge or a threat influences attainment value and academic self-efficacy. Learning and Instruction, v.40, p.21-28, aug. 2015.

RICHARDSON, Laurel. New writing practices in qualitative research. Sociology of Sport Journal, v.17, n.1, p.5-20, mar. 2000.

SHARMA, Jaya. Reflections on the Construction of Heteronormativity. Development, v.52, n.1, p.52-55, 2009.

SMITH, Brett et al. Understanding physical activity in spinal cord injury rehabilitation: translating and communicating research through stories. Disability and Rehabilitation, v.35, n.24, p.20462055, jun. 2013.

SPARKES, Andrew. Ethnography and the senses: challenges and possibilities. Qualitative Research in Sport and Exercise, v.1, n.1, 21-35, mar. 2009.

SPARKES, Andrew; SMITH, Brett. Inhabiting different bodies over time: Narrative and pedagogical challenges. Sport, education and society, v.16, n.3, p.357-370, jun. 2011.

SPARKES, Andrew; SMITH, Brett. Qualitative research methods in sport, exercise and health: from process to product. New York: Routledge, 2014.

TAMMINEN, Katherine; Bennett, Erica. No emotion is an island: an overview of theoretical perspectives and narrative research on emotions in sport and physical activity. Qualitative Research in Sport, Exercise and Health, 2016. DOI: 10.1080/2159676X.2016.1254109.

TAMMINEN, Katherine et al. Exploring emotions as social phenomena among Canadian varsity athletes. Psychology of Sport and Exercise, v.27, p.28-38, jul. 2016.

VIDIELLA, Judit et al. Masculinidad hegemónica, deporte y actividad física. Movimento, v.16, n.4, p.93-115, out./dez. 2010. 
